\title{
Increased Calcium-Sensing Receptor Immunoreactivity in the Hippocampus of a Triple Transgenic Mouse Model of Alzheimer's Disease
}

\author{
Emanuela Gardenal ${ }^{1,2,3}$, Anna Chiarini ${ }^{1}$, Ubaldo Armato ${ }^{1}$, Ilaria Dal Prà ${ }^{1}$ \\ Alexei Verkhratsky ${ }^{2,3,4}$ and José J. Rodríguez ${ }^{2,3 *}$ \\ ${ }^{1}$ Human Histology and Embryology Unit, Medical School, University of Verona, Verona, Italy, ${ }^{2}$ Basque Foundation for \\ Science, Achúcarro Basque Center for Neuroscience, IKERBASQUE, Billbao, Spain, ${ }^{3}$ Department of Neuroscience, \\ University of the Basque Country (UPV/EHU), Leioa, Spain, ${ }^{4}$ Faculty of Biology, Medicine and Health, The University of \\ Manchester, Manchester, UK
}

OPEN ACCESS

Edited by:

Wendy Noble

King's College London, UK

Reviewed by:

Flavia Eugenia Saravia,

IBYME CONICET and Faculty of Natural and Exact Sciences, Buenos

Aires University, Argentina

Ricardo Martinez-Murillo,

Consejo Superior de Investigaciones

Cientificas, Spain

Daniela Rossi,

Istituti Clinici Scientifici Maugeri Spa

$S B$, Italy

*Correspondence: José J. Rodríguez j.rodriguez-arellano@ikerbasque.org

Specialty section This article was submitted to Neurodegeneration,

a section of the journal

Frontiers in Neuroscience

Received: 15 December 2016 Accepted: 03 February 2017 Published: 16 February 2017

Citation:

Gardenal E, Chiarini A, Armato U, Da Prà I, Verkhratsky A and Rodríguez JJ (2017) Increased Calcium-Sensing

Receptor Immunoreactivity in the Hippocampus of a Triple Transgenic Mouse Model of Alzheimer's Disease.

Front. Neurosci. 11:81.

doi: 10.3389/fnins.2017.00081
The Calcium-Sensing Receptor (CaSR) is a G-protein coupled, 7-transmembrane domain receptor ubiquitously expressed throughout the body, brain including. The role of CaSR in the CNS is not well understood; its expression is increasing during development, which has been implicated in memory formation and consolidation, and CaSR localization in nerve terminals has been related to synaptic plasticity and neurotransmission. There is an emerging evidence of CaSR involvement in neurodegenerative disorders and Alzheimer's disease (AD) in particular, where the over-production of $\beta$-amyloid peptides was reported to activate CaSR. In the present study, we performed CaSR immunohistochemical and densitometry analysis in the triple transgenic mouse model of $A D(3 x T g-A D)$. We found an increase in the expression of CaSR in hippocampal CA1 area and in dentate gyrus in the 3xTg-AD mice when compared to non-transgenic control animals. This increase was significant at 9 months of age and further increased at 12 and 18 months of age. This increase paralleled the accumulation of $\beta$-amyloid plaques with age. Increased expression of CaSR favors $\beta$-amyloidogenic pathway following direct interactions between $\beta$-amyloid and CaSR and hence may contribute to the pathological evolution of the AD. In the framework of this paradigm CaSR may represent a novel therapeutic target.

Keywords: Alzheimer's disease, $\beta$-amyloid, tau, calcium sensing receptor (CaSR), hippocampus

\section{INTRODUCTION}

The calcium sensing receptor (CaSR) belongs to the extended family of plasmalemmal G proteincoupled heptahelical receptors (GPCRs); it shares the C subfamily of GPCRs with metabotropic glutamate receptors (mGluR) and $\gamma$-aminobutyric acid GABA receptors (Brown and MacLeod, 2001). CaSRs are widely distributed throughout the brain, with highest expression in the

Abbreviations: AD, Alzheimer's disease; ANOVA, One-way Analysis of Variance; CaSR, Calcium-Sensing Receptor; DG, Dentate Gyrus; GCL, Granular Cell Layer; IOD, Inverted Optical Density; mGluR, metabotrobic Glutamate Receptors; ML, Molecular Layer; OD, Optical Density; PB, Phosphate Buffer; PCL, Pyramidal Cell Layer; S.Mol, Stratum LacunosumMoleculare; SO, Stratum Oriens; S.Rad, Stratum Radiatum; TS, Trizma-base Saline; VEGF, Vascular Endothelial Growth Factor; 3xTg-AD, triple Transgenic mouse model of AD. 
subfornical organ, hippocampus, striatum, cingulate cortex, cerebellum, ependymal zones of the cerebral ventricles and perivascular nerves around cerebral arteries, some CaSR expressing cells were found also in rat dorsal root ganglia (Ruat et al., 1995; Yano et al., 2004). The CaSR has been found abundantly expressed in vivo in neurons and in oligodendrocytes; in vitro studies demonstrated its expression in human primary astrocytes and in rat microglia (Ruat et al., 1995; Chattopadhyay et al., 1998, 1999a; Ferry et al., 2000; Dal Prà et al., 2005).

Numerous functions have been assigned to CaSR in the CNS from regulation of neuronal growth and migration, to the role in neurotransmission and synaptic plasticity (Ruat and Traiffort, 2013); CaSR can also contribute to astroglial functions, microglial reactivity and oligodendroglial development (Ruat and Traiffort, 2013). The level of extracellular ionized $\mathrm{Ca}^{2+}$ $\left(\left[\mathrm{Ca}^{2+}\right]_{\mathrm{o}}\right)$ is usually considered to be stable in the brain, which is not really the case, since $\left[\mathrm{Ca}^{2+}\right]_{0}$ undergoes rapid fluctuations in normal physiological processes such as development, synaptic transmission and aging as well as in pathological processes including neurodegeneration and Alzheimer's disease (AD; Small, 2009; Ruat and Traiffort, 2013).

Expression of CaSR markedly increases during development, specifically in perinatal and early post-natal periods just before and after birth (Chattopadhyay et al., 1997; Vizard et al., 2008). In the hippocampus CaSR was reported to regulate neuronal growth, as well as extension and branching of neurites (Vizard et al., 2008). In addition, CaSR has been identified in neocortical nerve terminals where it senses the $\left[\mathrm{Ca}^{2+}\right]_{\mathrm{o}}$ and activates voltage dependent non-selective cation channels (NSCCs) (Chen et al., 2010). It has been proposed that the decrease in $\left[\mathrm{Ca}^{2+}\right]_{0}$ in the synaptic cleft may act as feedback to presynaptic CaSR and the associated increased activity of NSCCs may prolong action potentias; in this way CaSR may influence synaptic transmission through a homeostatic pathway to prevent synaptic failure when $\left[\mathrm{Ca}^{2+}\right]_{\mathrm{o}}$ falls (Ye et al., 1996). Studies in vitro conducted in the human astrocytoma cell line U87, and in primary cultures of rat microglia and oligodendroglia showed that CaSR stimulates $\mathrm{Ca}^{2+}$-activated $\mathrm{K}^{+}$channels, thus contributing to local ionic homeostasis following the lowering of $\left[\mathrm{Ca}^{2+}\right]_{0}$ due to increased neuronal activity; there are also indications that CaSR could also play a role in microglia activation (Chattopadhyay et al., 1998, 1999a,b). CaSR can form heterodimers with others GPCRs, like $\mathrm{GABA}_{\mathrm{B}}$ receptors and mGluRs, which might be important for their trafficking to the membrane, their ligand binding sensitivity and thus the regulation of signaling responses (Gama et al., 2001; Chang et al., 2007). Activation of CaSR was also demonstrated to induce a distinct form of glutamate release independent on $\mathrm{Ca}^{2+}$ influx (Vyleta and Smith, 2011).

In the context of $\mathrm{AD}, \mathrm{CaSR}$ has been reported to be directly activated by $\beta$-amyloid as well as by apoE (isoforms 3 and 4 ) (Conley et al., 2009). In rat hippocampal neurons exposure to $\beta$ amyloid stimulated openings of NSCCs linked to CaSR activation (Ye et al., 1997). How $\beta$-amyloid interacts with CaSR remains unclear, although it is possible that either $\beta$-amyloid fibrils or variously sized oligomers, having regular positive charges, mimic CaSR agonists, or hydrophobic interactions between $\beta$-amyloid and CaSR may take place (Ye et al., 1997). Thus, extracellular accumulation of $\beta$-amyloid can activate CaSR which, in turn, may contribute to $\mathrm{Ca}^{2+}$ dyshomeostasis observed in $\mathrm{AD}$ (Lim et al., 2014, 2015).

Previous studies on human cultured primary adult astrocytes showed that their exposure to exogenous $\beta$-amyloid $25-35$, a surrogate of $\beta$-amyloid 42 , triggers CaSR-dependent signaling cascade that stimulates the expression of nitric oxide synthase2 (NOS-2) followed by an excessive release of nitric oxide (Chiarini et al., 2005), and increased expression of vascular endothelial growth factor (VEGF)-A (Chiarini et al., 2010). Most importantly, cultured human cortical astrocytes and neurons exposed to $\beta$-amyloid $25-35$, which binds and activates CaSR (Dal Prà et al., 2014), begin to excessively produce and secrete $\beta$ amyloid $_{42}$ oligomers, contributing in this way to the $\beta$-amyloid load (Dal Prà et al., 2011; Armato et al., 2013).

In the present study, for the first time we aimed to determine in vivo CaSR expression in the $3 \mathrm{xTg}-\mathrm{AD}$ mouse model and correlate its changes with $\beta$-amyloid load.

\section{MATERIALS AND METHODS}

All animal procedures were carried out in accordance with the United Kingdom Animals (Scientific Procedures) Act of 1986 under the license from the Home Office. All efforts were made to reduce the number of animals by following the 3 R's (reduction, refinement and replacement).

\section{Mice}

Experiments were performed on male $3 \mathrm{xTg}$-AD mice generated on 129/C57BL6 background (the wild type of which was employed as a non-Tg control). The 3xTG-AD mice harbor the mutant genes for amyloid precursor protein (APPSwe), presenilin 1 PS1M146V and tauP301L (Oddo et al., 2003a,b; Rodríguez et al., 2008). All 3xTg-AD and non-Tg control mice were obtained by crossing homozygous breeders. Animals were housed in groups of the same genotype and in the same cage according to their age, kept in $12 \mathrm{~h}$ light-dark cycles with ad libitum access to food and water.

The experimental groups chosen were of 9, 12, and 18 months of age, since it is at these ages that the amyloid and tau pathologies emerge resembling the human Alzheimer's disease progression. Indeed, the $3 \times \mathrm{Tg}-\mathrm{AD}$ mice exhibit the highest intracellular $\beta$-amyloid deposition at 9 months of age, they start showing extracellular $\beta$-amyloid plaques followed by intracellular tau deposition at 12 months of age and they present massive $\mathrm{A} \beta$ plaques and neurofibrillary tangles at 18 months of age (Rodríguez et al., 2008; Olabarria et al., 2010).

\section{Fixation and Tissue Processing}

As described previously (Olabarria et al., 2010; KulijewiczNawrot et al., 2012) 3xTg-AD and non-Tg control mice at 9, 12,18 months of age (Ns for non-Tg $=5,5,4$; ns for $3 \times \mathrm{xg}^{-}$ $\mathrm{AD}=4,5,3$, respectively) were intraperitoneally anesthetized with sodium pentobarbital $(50 \mathrm{mg} / \mathrm{kg})$. Mice were trans-cardially perfused with $4 \%$ paraformaldehyde (PFA, Sigma, UK) and $0.1 \mathrm{M}$ phosphate buffer (PB) at $\mathrm{pH}$ 7.4. Brains were removed and post-fixed in $4 \%$ paraformaldehyde overnight, then cut 


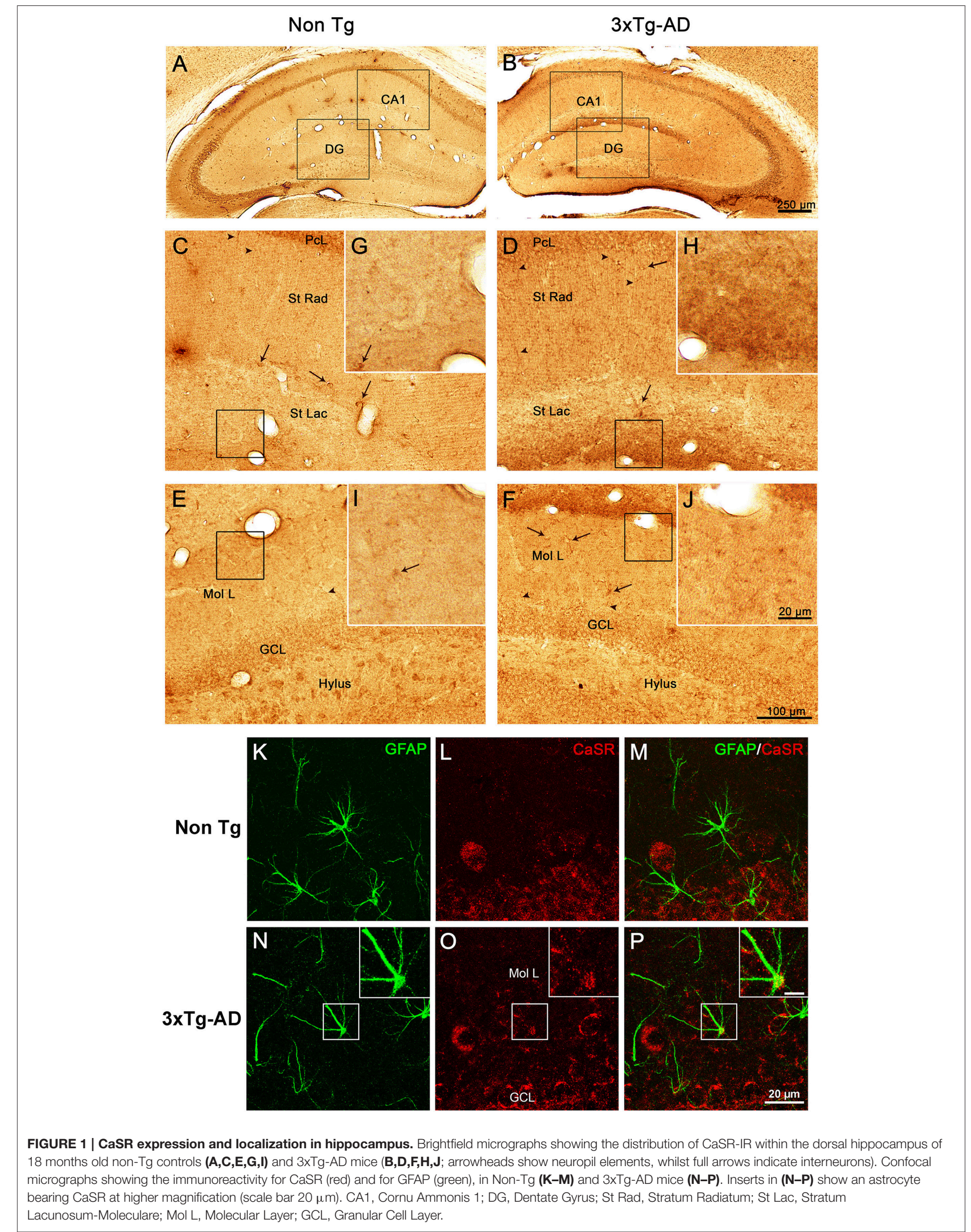


into 4-5 $\mathrm{mm}$ coronal slabs of tissue containing the entire rostrocaudal extent of the hippocampus, as previously described (Olabarria et al., 2011). The tissue was further sectioned in 40$50 \mu \mathrm{m}$-thick slices with a vibrating microtome (VT1000S, Leica, Milton Keynes, UK). Free floating sections were collected in $0.1 \mathrm{M} \mathrm{PB}$ and stored in a cryoprotectant solution containing $25 \%$ sucrose and $3.5 \%$ glycerol in $0.05 \mathrm{M} \mathrm{PB}$ at $\mathrm{pH} 7.4$. Three coronal sections at levels $-1.58 \mathrm{~mm} /-2.46 \mathrm{~mm}$ (dorsal hippocampus) posterior to Bregma, were selected from each animal for immunohistochemistry according to the mouse brain atlas of Paxinos and Franklin (2012).

\section{Antibodies}

A mouse monoclonal anti-Calcium Sensing Receptor antibody (anti-CaSR; Sigma-Aldrich, UK; C0493) was used for the determination of CaSR expression throughout the dorsal hippocampus. For the identification of intracellular $\beta$-amyloid deposits and plaques a monoclonal mouse antibody that reacts with abnormally processed isoforms, as well as precursor forms of $A \beta$, recognizing an epitope within amino acids 3-8 (EFRHDS; anti-A $\beta$ 6E10 [SIG-39320] Signet Laboratories, Dedham, MA) was used, for hyperphosphorylated Tau we employed the mouse monoclonal antibody anti-PHF Tau AT8 (Innogenetics, Gent, Belgium). For double immunostaining of CaSR with GFAP and $\mathrm{A} \beta$, a rabbit anti-GFAP (Sigma-Aldrich, UK; G9269) and a mouse anti-A $\beta$ Alexa 488 6E10 conjugated antibody (Covance, USA) were used. To assess for non-specific background labeling or cross reactivity between antibodies derived from different host species, a series of control experiments were performed, including the omission of primary (Supplementary Figure 1C) and/or secondary antibodies from the incubation solutions; resulting all of them in a total absence of target labeling.

\section{Immunohistochemistry}

All the sections were processed at the same time using the same experimental conditions to minimize methodological variability (Noristani et al., 2010; Olabarria et al., 2011; Kulijewicz-Nawrot et al., 2012). Then sections were incubated for $30 \mathrm{~min}$ in $30 \%$ methanol in $0.1 \mathrm{MPB}$ and $30 \%$ hydrogen peroxide $\left(\mathrm{H}_{2} \mathrm{O}_{2}\right.$; Sigma, UK). Sections were then rinsed with $0.1 \mathrm{M} \mathrm{PB}$ for 5 min and placed in $1 \%$ sodium borohydride (Sigma, UK) for 30 min. The sections were then washed with PB profusely before rinsing in $0.1 \mathrm{M}$ Trizma base saline (TS) for $10 \mathrm{~min}$. Brain sections were then incubated in $0.5 \%$ bovine serum albumin (Sigma, UK) in $0.1 \mathrm{M}$ TS and $0.25 \%$ Triton X-100 (Sigma, UK) for $30 \mathrm{~min}$. Sections were incubated for $72 \mathrm{~h}$ at room temperature in primary antibody (mouse anti-CaSR, 1:250, Sigma, UK). The sections were rinsed in $0.1 \mathrm{M}$ TS for $30 \mathrm{~min}$ and incubated in 1:400 dilutions of biotinylated horse anti-mouse IgG (Vector Laboratories, Peterborough, UK) for 1 $h$ at room temperature. Sections were rinsed with $0.1 \mathrm{M}$ TS for $30 \mathrm{~min}$ followed by incubation for $30 \mathrm{~min}$ in avidin-biotin peroxidase complex (Vector Laboratories, Peterborough, UK). The peroxidase reaction product was visualized by incubation in a solution containing $0.022 \%$ of $3,3^{\prime}$ diaminobenzidine (DAB, Aldrich, Gilligham, UK) and $0.003 \% \mathrm{H}_{2} \mathrm{O}_{2}$ for $7 \mathrm{~min}$. The reaction was stopped by rinsing the sections in $0.1 \mathrm{M}$ TS
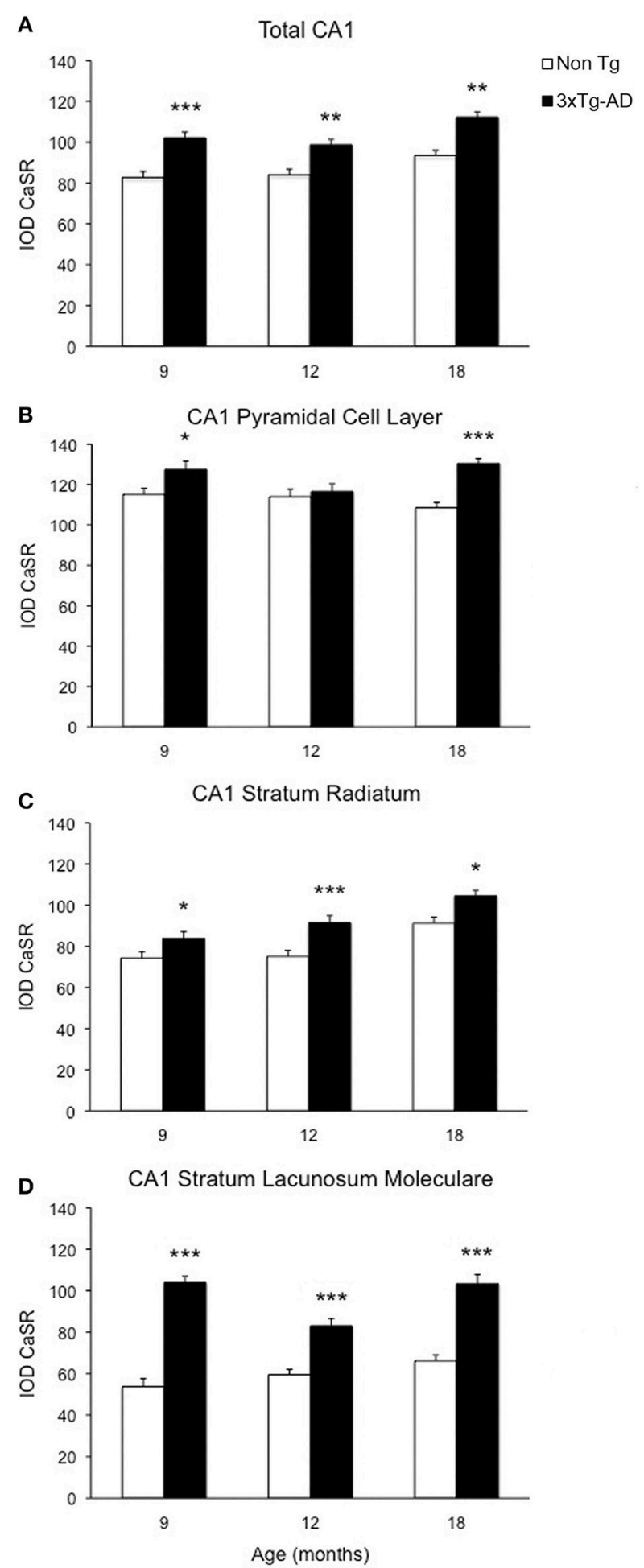

FIGURE 2 | Changes of CaSR expression in hippocampal CA1. Bar graphs illustrating CaSR-IR IOD within CA1 subfield of hippocampus between non- $\mathrm{Tg}$ controls and 3xTg-AD mice at 9, 12 and 18 months of age (Ns for non- $\mathrm{Tg}=5,5$, 4; ns for 3xTg-AD = 4, 5, 3, respectively; 3 slices have been analyzed per each animal). (A) Total CA1, (B) CA1 Pyramidal Cell Layer, (C) CA1 Stratum Radiatum, (D) CA1 Stratum Lacunosum-Moleculare. Bars represent means \pm SEM $\left({ }^{\star} p \leq 0.05,{ }^{* \star} p \leq 0.01,{ }^{\star \star *} p \leq 0.001\right)$. 
TABLE 1 | Summary of CaSR IOD values in the hippocampal CA1 and DG subfields and their respective layers in both non-Tg and 3xTg-AD.

\begin{tabular}{|c|c|c|c|c|c|c|}
\hline CaSR IOD & 9 months NTG & 9 months $3 \times T G-A D$ & 12 months NTG & 12 months 3xTG-AD & 18 months NTG & 18 months $3 \times T G-A D$ \\
\hline Total CA1 & $82.71 \pm 2.98$ & $102.1 \pm 2.72^{\star \star \star}$ & $83.92 \pm 2.51$ & $98.71 \pm 2.56^{\star \star \star}$ & $93.51 \pm 3.39$ & $112.30 \pm 4.68^{\star \star}$ \\
\hline PCL CA1 & $115.20 \pm 3.78$ & $127.50 \pm 3.80^{\star}$ & $114.00 \pm 2.49$ & $116.60 \pm 2.39 n s$ & $108.60 \pm 4.57$ & $130.50 \pm 3.40^{\star \star}$ \\
\hline St Rad CA1 & $74.23 \pm 2.91$ & $83.83 \pm 3.60^{*}$ & $75.08 \pm 2.85$ & $91.38 \pm 2.75^{\star \star \star}$ & $91.23 \pm 3.31$ & $104.5 \pm 5.99^{\star}$ \\
\hline St Lac CA1 & $53.78 \pm 2.60$ & $103.9 \pm 3.33^{\star \star \star}$ & $59.53 \pm 2.71$ & $83.09 \pm 4.41^{\star \star \star}$ & $66.25 \pm 5.31$ & $103.4 \pm 6.25^{\star \star \star}$ \\
\hline Total DG & $82.68 \pm 3.11$ & $97.41 \pm 3.56^{\star \star}$ & $81.35 \pm 3.33$ & $93.34 \pm 2.80^{\star \star}$ & $89.78 \pm 4.75$ & $108.40 \pm 4.96^{\star}$ \\
\hline ML & $73.06 \pm 3.16$ & $84.68 \pm 4.88^{*}$ & $80.58 \pm 4.18$ & $90.51 \pm 3.01^{*}$ & $90.00 \pm 4.11$ & $108.8 \pm 6.91^{\star}$ \\
\hline GCL & $98.30 \pm 3.55$ & $117.30 \pm 4.27^{\star \star}$ & $87.76 \pm 3.15$ & $97.13 \pm 2.78^{*}$ & $82.18 \pm 6.16$ & $112.90 \pm 3.54^{\star \star \star}$ \\
\hline
\end{tabular}

Values are expressed as means \pm SEM $\left({ }^{*} p \leq 0.05,{ }^{* *} p \leq 0.01,{ }^{* * *} p \leq 0.001\right)$.

for $5 \mathrm{~min}$ followed by $0.1 \mathrm{M} \mathrm{PB}$ for $15 \mathrm{~min}$. Brain sections were permanently mounted onto gelatinized slides and allowed to dry overnight. Sections were then dehydrated in ascending concentration of ethanol $(50,70,80,90,95$, and $100 \%)$ and, finally, xylene. Sections were then permanently mounted and coverslipped using Entellan (Merck KGaA, Darmstadt, Germany) and slides were left to dry overnight.

For the dual immunofluorescence labeling with CaSR and GFAP the sections were simultaneously incubated with both antibodies (mouse anti-CaSR, 1:250; rabbit anti-GFAP, 1:20,000) for $48 \mathrm{~h}$ at room temperature. Then CaSR and GFAP were detected in a sequential manner on the same sections by incubation of $2 \mathrm{~h}$ with Alexa Fluor 594-conjugated goat antimouse and Alexa Fluor 488-conjugated goat anti-rabbit (1:400, Invitrogen, Paisley, UK), respectively.

For the dual immunofluorescence labeling with CaSR and $\mathrm{A} \beta$ the sections were first incubated for $48 \mathrm{~h}$ at room temperature in CaSR antibody solution then in the Alexa 594 conjugated goat anti-mouse for $2 \mathrm{~h}$, finally for $24 \mathrm{~h}$ in Alexa 488 -conjugated mouse anti-A $\beta$ antibody (1:1,000, Covance, USA).

Sections were rinsed with $0.1 \mathrm{M}$ TS for $30 \mathrm{~min}$ and permanently mounted in an aqueous medium (Vectashield; Vector laboratories, Peterborough, UK).

\section{Optical Density (OD) Measurement}

Using computer-assisted imaging analysis (ImageJ 2.0.0-rc39/1.50b; NIH, USA) we analyzed the expression of CaSR by measuring its OD, as described previously (Cordero et al., 2005; Noristani et al., 2010, 2012). Briefly, to exclude any experimental errors and/or bias, all images were taken at constant light intensity with a Nikon Eclipse 80i microscope coupled with an 8001 MicroFIRE camera. Optical filters were used to ensure the specificity of the signal recorded by the camera. The OD was calculated from a relative scale of intensity ranking from 0 to 250 , with a measurement of 250 corresponding to the area with very low CaSR expression and 0 corresponding to the area with highest labeling. The calibration density was kept constant for measuring all sections to avoid experimental variances. Non-specific $\mathrm{OD}$ in sections was measured from the corpus callosum (CC). CaSR density of the complete CA subfields of the hippocampus and their different layers (stratum pyramidale, PCL; stratum oriens, SO; stratum radiatum, S.Rad and stratum lacunosum-moleculare, S.Mol), except CA3 where we also studied stratum lucidum, were measured independently. Similarly, CaSR density of the dentate gyrus (DG) and its different layers (granular cell layer, GCL, molecular layer, ML and hilus) were measured individually. The OD of the region of interest is determined by outlining each layer and obtaining the mean value of the intensities in the selected area (Supplementary Figures 1A,B). The changes in CaSR density were analyzed against a constant control region (CC): 250 was divided by control region and the obtained factor was multiplied by the region of interest in every given section. Inverse OD (IOD) was obtained by subtracting the OD (after the control region normalization) from 250 . Values of IOD were taken and averaged in both the left and right hemisphere of each slice. The results are shown as inverse optical CaSR density (IOD/pixel).

\section{Counting of $\mathrm{A} \beta$-Positive Cells}

$\beta$-amyloid containing neurons were counted in the entire extent of the CA1 region of the hippocampus, since this field shows the earliest and strongest accumulation of $A \beta$ intracellular deposits. This quantification was carried out on six non-consecutive sections from dorsal hippocampus of three non-Tg and 3xTg-AD animals of 9 months of age immunolabeled with anti-A $\beta 6 \mathrm{E} 10$ antibody.

\section{Statistical Analysis}

One-way analysis of variance (ANOVA) was used to determine changes in CaSR density between 3xTg-AD animals and their non-transgenic controls at different ages, followed by unpaired $t$-test comparisons at the different time points. Significance was accepted at $P \leq 0.05$. The data were analyzed using GraphPad Prism software (La Jolla, CA, USA). Results are expressed as mean \pm SEM.

\section{RESULTS}

Immunohistochemical labeling demonstrated that CaSR is present in the hippocampus of both $3 \times \mathrm{Tg}-\mathrm{AD}$ and non-Tg control animals at all ages $(9,12$, and 18 months) with a rather homogeneous distribution throughout all hippocampal areas (Figures 1A,B). Punctate CaSR labeling is mainly present in pyramidal neurons of the different CA subfields and in granule cells of the DG as well as in the pleomorphic cells of the hilus, being more evident in the soma, nucleus excluded, although it 
is also detectable in the neuropil, including both dendrites and axons (Figures 1C-F). Astroglial occurrence of CaSR was rather rare and when detected was of very low intensity as compared to neurons; appearing as puncta mainly restricted to the astrocytic soma (Figures 1K-P).

\section{Increase of CaSR Expression in 3xTg-AD Animals}

Optical density analysis of CaSR staining in the hippocampus of the 3xTg-AD mouse showed a significant increase in its expression in CA1 and DG subfields $\left[F_{(7,166)}=11.32, p<0.0001\right.$ and $F_{(7,166)}=7.994, p<0.0001$, respectively] at all ages $(9$, 12, and 18 months; Figures 1, 2). An increase in CaSR optical density of $23.44,17.62$, and $20.09 \%$ at 9,12 , and 18 months of age respectively when compared to control non-Tg animals was detected in CA1 area (Figures 1C,D, 2A; Table 1). Similar increase in CaSR optical density was observed in DG: 17.82, 14.74 , and $20.74 \%$, at 9,12 , and 18 months respectively in $3 \times \mathrm{Tg}-$ $\mathrm{AD}$ animals compared to non-Tg (Figures 1E,F, 3A; Table 1). No significant alterations in the optical density of CaSR were identified in the CA2 and in CA3 sub-fields.

\section{CaSR Expression Increase in CA1 and DG Is Layer-Specific}

In CA1 we found that the increase in CaSR expression in 3xTg$\mathrm{AD}$ animals mainly occurred in the pyramidal cell layer (PCL, $10.68 \%$ at 9 months, $2.28 \%$ at 12 months, $20.17 \%$ at 18 months; Figure 2B), in the stratum radiatum (SR, $12.93 \%$ at 9 months, $27.71 \%$ at 12 months, $14.55 \%$ at 18 months; Figure 2C) and in the stratum lacunosum moleculare (SLM, 93.19\% at 9 months, $39.58 \%$ at 12 months, $56.08 \%$ at 18 months; Figures 1G,H, 2D; Table 1).

In the DG an increase in CaSR expression was most prominent in the molecular layer (ML) of 3xTg-AD animals respect to their controls (15.90\% at 9 months, $12.32 \%$ at 12 months, $20.98 \%$ at 18 months; Figure 3B) and in the granular cell layer (GCL, $19.33 \%$ at 9 months, $10.68 \%$ at 12 months, $37.38 \%$ at 18 months; Figures 1I,J, 3C; Table 1). The increase in the molecular layer was similar in all subdivisions; the inner, middle and outer ML (data not shown).

Increased level of CaSR labeling in the projections layers described above doesn't appear to derive from neuronal somata, despite its presence in some interneurons cell bodies, but mainly from the neuropil comprising both dendrites and axons (Figures 1D,F).

\section{CaSR Increase in Hippocampus Occurs in the Areas Affected by $\beta$-Amyloid Accumulation}

In $3 x T g-A D$ mice intracellular $\beta$-amyloid in hippocampal neurons appears between 4 and 6 months of age and reaches its maximum at 9 months of age (Figures $4 \mathbf{G}, \mathbf{H}$ ); extracellular $\beta$-amyloid depositions start to mount from 9 to 12 months, being maximal at 18 months. At 18 months the $\beta$-amyloid plaques are big and expanded through the hippocampus mainly concentrating in the CA1 subfield (Figures 4E,F,I,J); with later
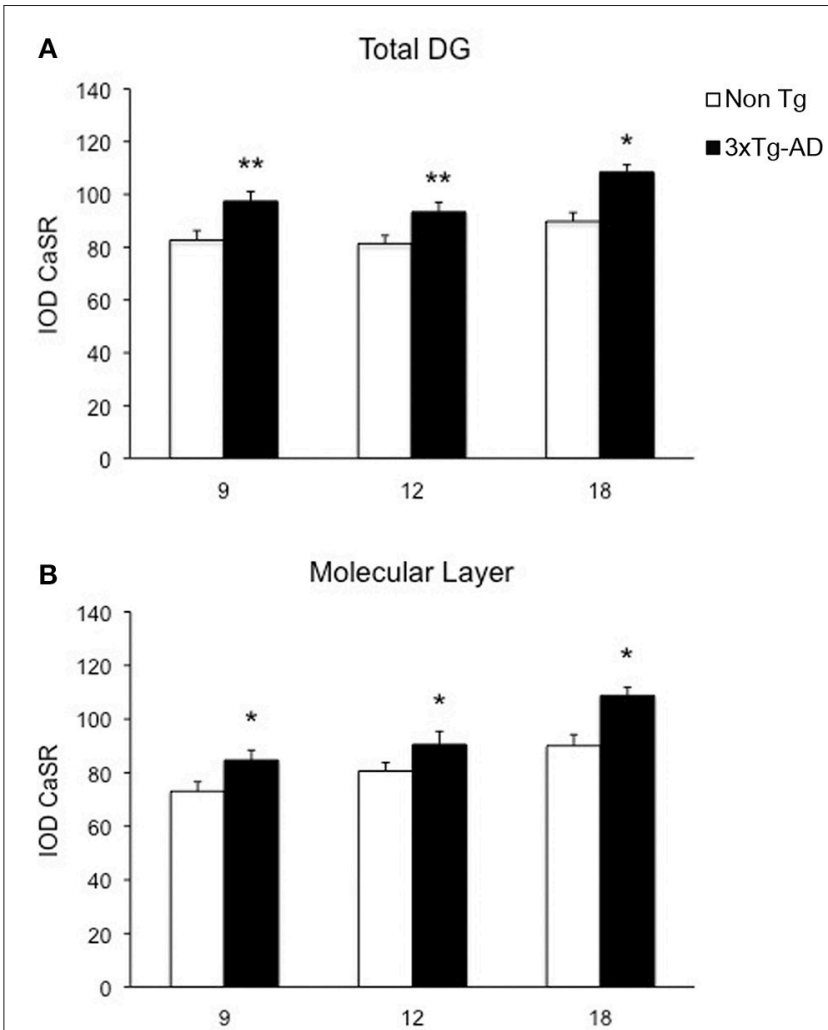

C Granular Cell Layer

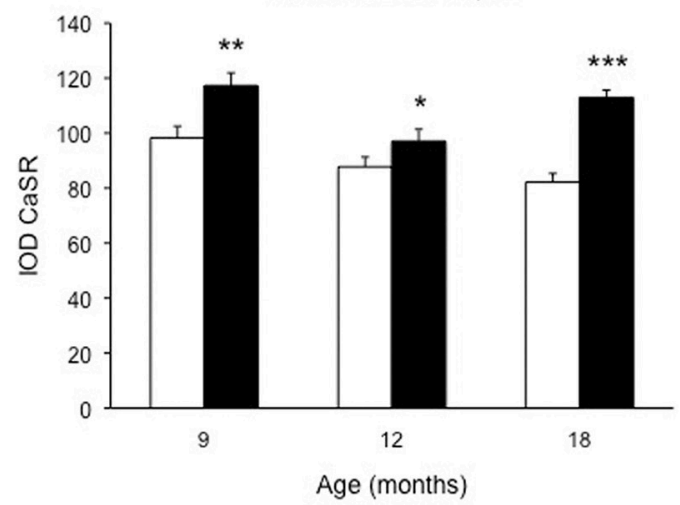

FIGURE 3 | Modification of CaSR expression in hippocampal DG. Bar graphs illustrating CaSR-IR IOD within DG subfield between non-Tg controls and $3 \times \mathrm{Tg}-\mathrm{AD}$ mice at 9, 12, and 18 months of age (Ns for non- $\mathrm{Tg}=5,5,4$; ns for $3 \times \operatorname{Tg}-\mathrm{AD}=4,5,3$, respectively; 3 slices have been analyzed per each animal). (A) Total DG; (B) Molecular Layer; (C) Granular Cell Layer. Bars represent means \pm SEM $\left({ }^{*} p \leq 0.05,{ }^{* *} p \leq 0.01,{ }^{* * *} p \leq 0.001\right)$.

appearance in the DG (Noristani et al., 2012; Rodríguez et al. 2013). In a similar way hyper-phosphorylated Tau protein begins to be detectable in $3 \times \mathrm{Tg}-\mathrm{AD}$ mice at 12 months causing the formation of tangles by 18 months, and it is also concentrated in CA1 region affecting all the layers (Figures $4 \mathbf{K}, \mathbf{L}$ ). The increase of CaSR intensity in the CA1 region follows the same spatiotemporal pattern as that of $\beta$-amyloid deposition (Figures $4 \mathbf{A}-\mathbf{F}$ ), 

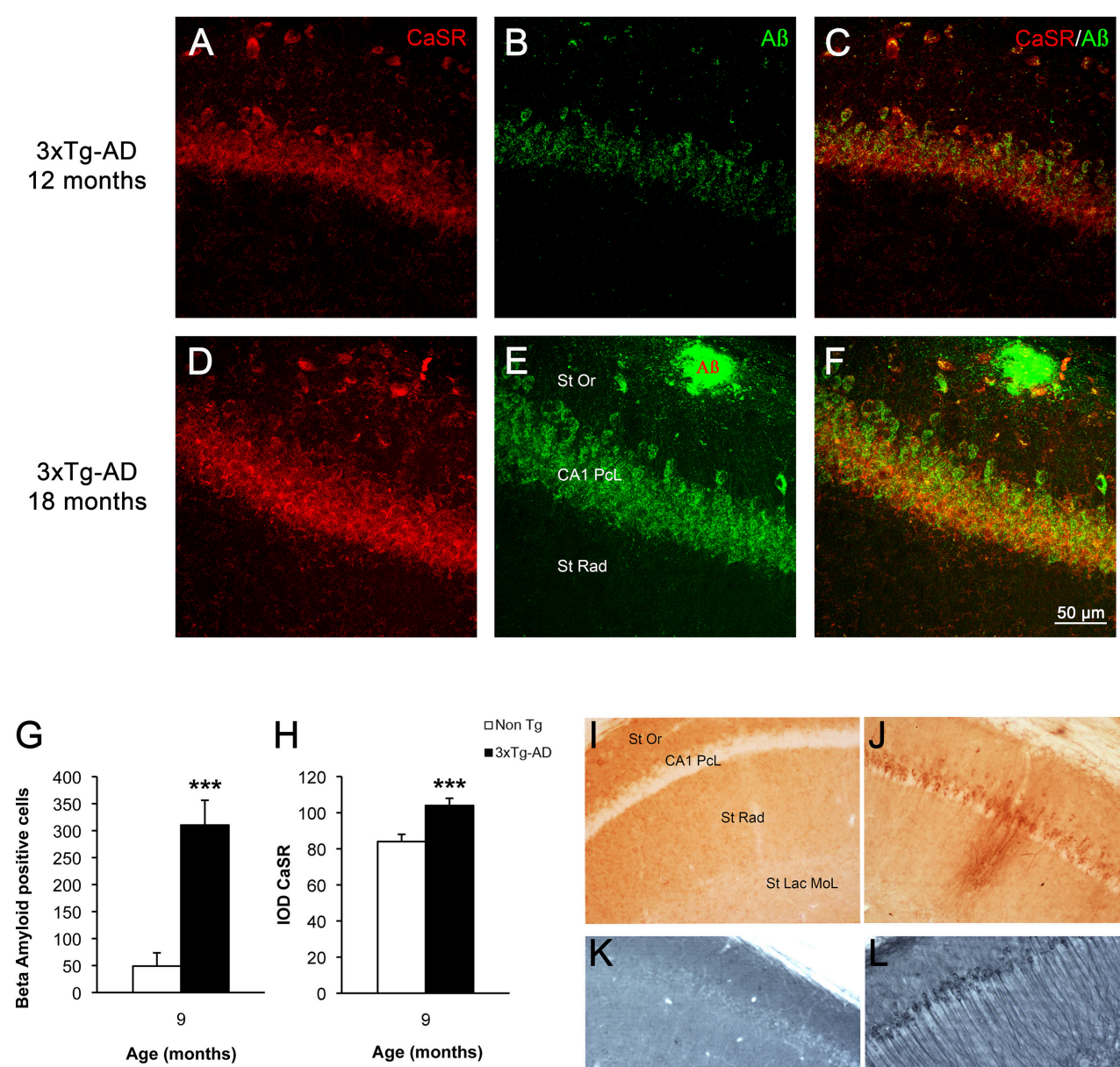

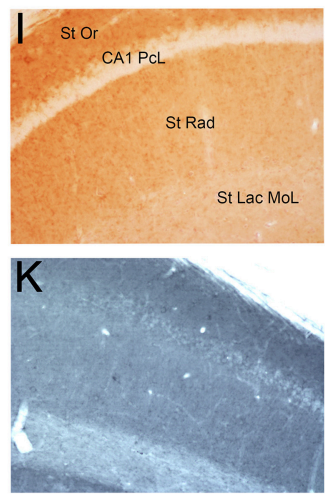

12 months Non $\mathrm{Tg}$
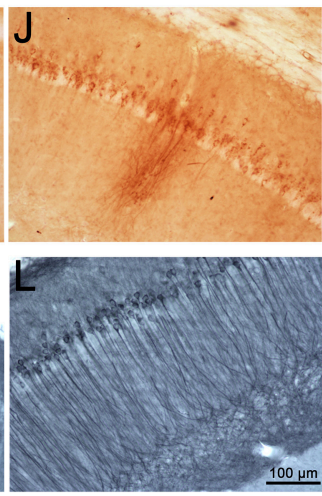

12 months $3 \times T g-A D$

FIGURE 4 | CaSR and $\beta$-amyloid relationship in hippocampus during AD progression. Confocal micrographs showing the overlapping expression of CaSR (red) with the accumulation of intraneuronal $A \beta$ (green, anti-A $\beta$ 488) and the formation of plaques in hippocampal pyramidal neurons of $3 \times T$ Tg-AD mice of 12 and 18 months of age respectively. (A,D) CaSR-IR; (B,E) A $\beta$-IR; (C,F) merge. St Or Stratum Oriens; CA1 PcL CA1 Pyramidal Cell Layer; St Rad Stratum Radiatum. Bar graphs illustrating the number of $A \beta$ positive cells $(\mathbf{G})$ and the IOD of CaSR $\mathbf{( H )}$ within CA1 subfield of hippocampus between non-Tg controls and $3 \times$ Tg-AD mice at 9 months of age $\left({ }^{\star \star \star} p \leq 0.001\right)$. Brightfield micrographs of CA1 areas of hippocampus of non-Tg and 3xTg-AD mice immunolabeled with anti-A $\beta$ (I,J) and anti-Tau antibody $\mathbf{( K , L )}$ at 12 months of age. St Or, Stratum Oriens; CA1 PcL, CA1 Pyramidal Cell Layer; St Rad, Stratum Radiatum; St Lac Mol, Stratum Lacunosum Moleculare.

while in the DG it appears even before the accumulation of $A \beta$ becomes evident.

\section{DISCUSSION}

In vitro exposure of human cortical astrocytes and neurons to a truncated form of $\beta$-amyloid, the $A \beta_{25-35}$ peptide, which binds and activates the CaSR (Dal Prà et al., 2014), stimulated the intracellular production and secretion of $\beta$-amyloid by both cell types with the subsequent death of a fraction of neurons (Armato et al., 2013). While neurons were vulnerable to $\beta$-amyloid toxicity, cultured astrocytes survived and they showed a transient increase of CaSR expression. The cytotoxic effects on neurons were fully inhibited following addition of CaSR antagonist NPS 2143 to the incubation media. Indeed, the NPS prevented the death of neurons and it deeply and steadily downregulated the receptor in the $\mathrm{A} \beta$-treated astrocytes, and completely blocked the A $\beta$ self-induction mechanism (Armato et al., 2013).

This in vitro study conceptually complements results we obtained in the $3 \mathrm{xTg}$-AD mice model described in the present paper; these results further corroborate links existing between increases in CaSR expression and $\beta$-amyloid accumulation. In the $3 \times \mathrm{Tg}$-AD mice, intraneuronal $\beta$-amyloid starts to accumulate in the CA1 pyramidal neurons at 4-6 months of age reaching maximum at 9 months of age, while extracellular $\beta$-amyloid deposits emerge from 12 months of age. Appearance of senile plaques is associated with specific astrogliosis around the plaques despite the generalized hippocampal astrocytic atrophy and with an increase in the density of activated microglia and recruitment of new ramified microglial cells (Rodríguez et al., 2009, 2010, 
2013; Olabarria et al., 2010). Accumulation of Tau that occurs later follows similar pattern with maximum presence from 18 months. The 3xTg-AD mouse model not only develops the typical histopathological hallmarks of Alzheimer's disease, but also manifests synaptic dysfunction with impaired long-termpotentiation (LTP) (Oddo et al., 2003b; Rodríguez et al., 2008).

Analysis of an acute hypoxia/ischemia in rats revealed that $\mathrm{A} \beta$ overproduction due to hypoxic injury is mediated by CaSR hyperexpression (Bai et al., 2015). Experiments on rat hippocampal neurons demonstrated that hypoxia induces an up-regulation of CaSR which in turn promotes the elevation of cytosolic $\left[\mathrm{Ca}^{2+}\right]$ thereby producing an increase of BACE1 expression that results in the rise of $A \beta_{40}$ and $A \beta_{42}$ generation. In addition, specific inhibition of CaSR with Calhex 231, an allosteric antagonist of CaSR, induced a decrease of BACE1 and $\mathrm{A} \beta$ both in vitro and in vivo in hypoxic conditions (Bai et al., 2015). The prominent effect of the increased expression and activity of CaSR in hippocampus is confirmed also by analysing a mouse model of acute ischemic injury where a transient global cerebral ischemia (TGI) was induced. In this model CaSR was overexpressed in parallel with $\mathrm{GABA}_{B}$ receptor 1 downregulation and was followed by neuronal death. The administration of the calcilytic compound NPS89636 through intracerebroventricular injections after the TGI specifically blocked the activity of CaSR, restored $\mathrm{GABA}_{\mathrm{B}} \mathrm{R} 1$ expression and protected hippocampal neurons from cell death. Furthermore, the treatment of TGI mice with calcilytics significantly improved learning and memory (Kim et al., 2014).

Altogether these findings reveal the importance and the impact which altered expression of CaSR has on maintaining the normal brain function, supporting the idea that its changes could contribute to the development and progression of pathologies such as Alzheimer's disease and stroke. Our present data in an $\mathrm{AD}$ mouse model show that expression of CaSR is increasing while neuropathology progresses. Previous works demonstrated that the administration of $\mathrm{A} \beta_{42}$ oligomers to neuronal and astrocytic human cell cultures increases the endogenous $A \beta_{42}$ production and secretion resulting in a progressive death of neurons. This mechanism of $A \beta$ self-induction, which contribute to the advance of $\mathrm{AD}$, was demonstrated to be completely suppressed by adding a specific calcilytic like NPS 2143 to the cell culture (Armato et al., 2013; Dal Prà et al., 2015; Chiarini et al., 2016). It needs to be emphasized that the CaSR could

\section{REFERENCES}

Armato, U., Chiarini, A., Chakravarthy, B., Chioffi, F., Pacchiana, R., Colarusso, E., et al. (2013). Calcium-sensing receptor antagonist (calcilytic) NPS 2143 specifically blocks the increased secretion of endogenous $A \beta 42$ prompted by exogenous fibrillary or soluble A $\beta 25-35$ in human cortical astrocytes and neurons-Therapeutic relevance to Alzheimer's disease. Biochim. Biophys. Acta 1832, 1634-1652. doi: 10.1016/j.bbadis.2013.04.020

Bai, S., Mao, M., Tian, L., Yu, Y., Zeng, J., Ouyang, K., et al. (2015). Calcium sensing receptor mediated the excessive generation of $\beta$-amyloid peptide induced by hypoxia in vivo and in vitro. Biochem. Biophys. Res. Commun. 459, 568-573. doi: 10.1016/j.bbrc.2015.02.141 be a promising target of investigation for not only further understanding $\mathrm{AD}$ pathology onset and spread but also for evaluating new therapeutic solutions.

\section{AUTHOR CONTRIBUTIONS}

EG: Experimental work, data analysis, result preparation and writing of the manuscript. JR: Conception of the study, experimental design, data analysis, result preparation interpretation, discussion and writing of the manuscript. $\mathrm{AV}$ : Results interpretation and discussion and writing of the manuscript. AC, UA, and ID: Results interpretation and discussion.

\section{ACKNOWLEDGMENTS}

We thank Dr Fátima Zallo Díaz, for her help and assistance with the figures. Authors research was supported by Alzheimer's Research Trust (UK) Programme Grant [grant number ART/PG2004A/1 (to AV and JR)]; by the Grant Agency of the Czech Republic [grant number GACR 309/09/1696 (to JR); GACR 305/08/1381 and GACR 305/08/1384 (to AV)] as well as by the Spanish Government Plan Nacional de I+D+I 2008-2011, and ISCIII Subdirección General de Evaluación y Fomento de la investigación co-financed by FEDER [grant number PI10/02738 (to JR and AV)]. The Government of the Basque Country [grant number AE-2010-1-28; AEGV10/16, GV2011111020 (to JR)]; as well as by the Spanish Ministerio de Economía y Competitividad, RETOS Colaboración [grant number RTC-2015-3542-1 co-financed by FEDER (to JR)] and by the Ministry of Italian University and Research (MIUR) to $\mathrm{EG}, \mathrm{AC}, \mathrm{UA}$, and ID.

\section{SUPPLEMENTARY MATERIAL}

The Supplementary Material for this article can be found online at: http://journal.frontiersin.org/article/10.3389/fnins. 2017.00081/full\#supplementary-material

Supplementary Figure 1 | Brightfield micrographs showing the anatomy of the dorsal hippocampus in a section stained with toluidine blue (A) and the delimited areas that were chosen in each single analyzed section as region of interest for the $\mathrm{OD}$ analysis in a representative section of a 3xTg-AD animal labeled for CaSR (B) as detailed in the Materials and Methods. (C) Micrograph showing the lack of staining in the negative control, after omission CaSR antibody.

Brown, E. M., and MacLeod, R. J. (2001). Extracellular calcium sensing and extracellular calcium signaling. Physiol. Rev. 81, 239-297. Available online at: http://physrev.physiology.org/content/81/1/239.long

Chang, W., Tu, C., Cheng, Z., Rodriguez, L., Chen, T. H., Gassmann, M., et al. (2007). Complex formation with the type B $\gamma$-aminobutyric acid receptor affects the expression and signal transduction of the extracellular calciumsensing receptor: studies with HEK-293 cells and neurons. J. Biol. Chem. 282, 25030-25040. doi: 10.1074/jbc.M700924200

Chattopadhyay, N., Legradi, G., Bai, M., Kifor, O., Ye, C., Vassilev, P. M., et al. (1997). Calcium-sensing receptor in the rat hippocampus: a developmental study. Brain Res. Dev. Brain Res. 100, 13-21. doi: 10.1016/S0165-3806(97)00009-6 
Chattopadhyay, N., Ye, C. P., Yamaguchi, T., Kifor, O., Vassilev, P. M., Nishimura, R., et al. (1998). Extracellular calcium-sensing receptor in rat oligodendrocytes: expression and potential role in regulation of cellular proliferation and an outward $\mathrm{K}^{+}$channel. Glia 24, 449-458. doi: 10.1002/ (SICI) 1098-1136(199812)24:4<449::AID-GLIA10>3.0.CO;2-9

Chattopadhyay, N., Ye, C. P., Yamaguchi, T., Vassilev, P. M., and Brown, E. M. (1999b). Evidence for extracellular calcium-sensing receptor mediated opening of an outward $\mathrm{K}^{+}$channel in a human astrocytoma cell line (U87). Glia 26 64-72. doi: 10.1002/(SICI)1098-1136(199903)26:1<64::AID-GLIA7>3. $0 . \mathrm{CO} ; 2-\mathrm{X}$

Chattopadhyay, N., Ye, C., Yamaguchi, T., Nakai, M., Kifor, O., Vassilev, P. M., et al. (1999a). The extracellular calcium-sensing receptor is expressed in rat microglia and modulates an outward $\mathrm{K}^{+}$channel. J. Neurochem. 72, 1915-1922. doi: 10.1046/j.1471-4159.1999.0721915.x

Chen, W., Bergsman, J. B., Wang, X., Gilkey, G., Pierpoint, C. R., Daniel, E. A., et al. (2010). Presynaptic external calcium signaling involves the calcium-sensing receptor in neocortical nerve terminals. PLOS ONE 5:e8563. doi: 10.1371/journal.pone. 0008563

Chiarini, A., Armato, U., Liu, D., and Dal Prà, I. (2016). Calcium-sensing receptors of human neural cells play crucial roles in Alzheimer's disease. Front. Physiol. 7:134. doi: 10.3389/fphys.2016.00134

Chiarini, A., Dal Pra, I., Menapace, L., Pacchiana, R., Whitfield, J., and Armato, U. (2005). Soluble amyloid $\beta$-peptide and myelin basic protein strongly stimulate, alone and in synergism with combined proinflammatory cytokines, the expression of functional nitric oxide synthase- 2 in normal adult human astrocytes. Int. J. Mol. Med. 16, 801-807 doi: 10.3892/ijmm.16.5.801

Chiarini, A., Whitfield, J., Bonafini, C., Chakravarthy, B., Armato, U., and Dal Prà, I. (2010). Amyloid- $\beta(25-35)$, an amyloid- $\beta(1-42)$ surrogate, and proinflammatory cytokines stimulate VEGF-A secretion by cultured, early passage, normoxic adult human cerebral astrocytes. J. Alzheimers. Dis. 21, 915-926. doi: 10.3233/JAD-2010-100471

Conley, Y. P., Mukherjee, A., Kammerer, C., DeKosky, S. T., Kamboh, M. I., Finegold, D. N., et al. (2009). Evidence supporting a role for the calcium-sensing receptor in Alzheimer disease. Am. J. Med. Genet. B Neuropsichiatr. Genet. 150B, 703-709. doi: 10.1002/ajmg.b.30896

Cordero, M. I., Rodríguez, J. J., Davies, H. A., Peddie, C. J., Sandi, C., and Stewart, M. G. (2005). Chronic restraint stress down-regulates amygdaloid expression of polysialylated neural cell adhesion molecule. Neuroscience 133, 903-910. doi: 10.1016/j.neuroscience.2005.03.046

Dal Prà, I., Chiarini, A., Gui, L., Chakravarthy, B., Pacchiana, R., Gardenal, E., et al. (2015). Do astrocytes collaborate with neurons in spreading the "Infectious" a and tau drivers of Alzheimer's disease? Neuroscientist 21, 9-29. doi: $10.1177 / 1073858414529828$

Dal Prà, I., Chiarini, A., Nemeth, E. F., Armato, U., and Whitfield, J. F. (2005). Roles of $\mathrm{Ca}^{2+}$ and the $\mathrm{Ca}^{2+}$-sensing receptor (CASR) in the expression of inducible NOS (nitric oxide synthase)-2 and its BH 4 (tetrahydrobiopterin)dependent activation in cytokine-stimulated adult human astrocytes. J. Cell. Biochem. 96, 428-438. doi: 10.1002/jcb.20511

Dal Prà, I., Chiarini, A., Pacchiana, R., Gardenal, E., Chakravarthy, B., Whitfield, J. F., et al. (2014). Calcium-sensing receptors of human astrocyte-neuron teams: amyloid- $\beta$-driven mediators and therapeutic targets of Alzheimer's disease. Curr. Neuropharmacol. 12, 353-364. doi: 10.2174/1570159X12666140828214701

Dal Prà, I., Whitfield, J. F., Pacchiana, R., Bonafini, C., Talacchi, A., Chakravarthy, B., et al. (2011). The amyloid- $\beta 42$ proxy, amyloid- $\beta(25-35)$, induces normal human cerebral astrocytes to produce amyloid- $\beta 42$. J. Alzheimer's Dis. 24, 335-347. doi: 10.3233/JAD-2011-101626

Ferry, S., Traiffort, E., Stinnakre, J., and Ruat, M. (2000). Developmental and adult expression of rat calcium-sensing receptor transcripts in neurons and oligodendrocytes. Eur. J. Neurosci. 12, 872-884. doi: $10.1046 /$ j.1460-9568.2000.00980.x

Gama, L., Wilt, S. G., and Breitwieser, G. E. (2001). Heterodimerization of calcium sensing receptors with metabotropic glutamate receptors in neurons. J. Biol. Chem. 276, 39053-39059. doi: 10.1074/jbc.M105662200

Kim, J. Y., Ho, H., Kim, N., Liu, J., Tu, C., Yenari, M. A., et al. (2014). Calciumsensing receptor (CaSR) as a novel target for ischemic neuroprotection. Ann. Clin. Transl. Neurol. 1, 851-866. doi: 10.1002/acn3.118
Kulijewicz-Nawrot, M., Verkhratsky, A., Chvátal, A., Syková, E., and Rodríguez, J. J. (2012). Astrocytic cytoskeletal atrophy in the medial prefrontal cortex of a triple transgenic mouse model of Alzheimer's disease. J. Anat. 221, 252-262. doi: $10.1111 / j .1469-7580.2012 .01536 . x$

Lim, D., Rodríguez-Arellano, J. J., Parpura, V., Zorec, R., Zeidán-Chuliá, F., Genazzani, A. A., et al. (2015). Calcium signalling toolkits in astrocytes and spatio-temporal progression of Alzheimer's disease. Curr. Alzheimer Res. 13, 359-369. doi: 10.2174/1567205013666151116130104

Lim, D., Ronco, V., Grolla, A. A., Verkhratsky, A., and Genazzani, A. A. (2014). Glial calcium signalling in Alzheimer's disease. Rev. Physiol. Biochem. Pharmacol. 167, 45-65. doi: 10.1007/112_2014_19

Noristani, H. N., Olabarria, M., Verkhratsky, A., and Rodríguez, J. J. (2010). Serotonin fibre sprouting and increase in serotonin transporter immunoreactivity in the CA1 area of hippocampus in a triple transgenic mouse model of Alzheimer's disease. Eur. J. Neurosci. 32, 71-79. doi: 10.1111/j.1460-9568.2010.07274.x

Noristani, H. N., Verkhratsky, A., and Rodríguez, J. J. (2012). High tryptophan diet reduces CAl intraneuronal $\beta$-amyloid in the triple transgenic mouse model of Alzheimer's disease. Aging Cell 11, 810-822. doi: 10.1111/j.1474-9726.2012.00845.x

Oddo, S., Caccamo, A., Kitazawa, M., Tseng, B. P., and LaFerla, F. M. (2003a). Amyloid deposition precedes tangle formation in a triple transgenic model of Alzheimer's disease. Neurobiol. Aging 24, 1063-1070. doi: 10.1016/j.neurobiolaging.2003.08.012

Oddo, S., Caccamo, A., Shepherd, J. D., Murphy, M. P., Golde, T. E., Kayed, R., et al. (2003b). Triple-transgenic model of Alzheimer's Disease with plaques and tangles: intracellular $A \beta$ and synaptic dysfunction. Neuron 39, 409-421. doi: 10.1016/S0896-6273(03)00434-3

Olabarria, M., Noristani, H. N., Verkhratsky, A., and Rodríguez, J. J. (2010). Concomitant astroglial atrophy and astrogliosis in a triple transgenic animal model of Alzheimer's disease. Glia 58, 831-838. doi: 10.1002/glia.20967

Olabarria, M., Noristani, H. N., Verkhratsky, A., and Rodríguez, J. J. (2011). Age-dependent decrease in glutamine synthetase expression in the hippocampal astroglia of the triple transgenic Alzheimer's disease mouse model: mechanism for deficient glutamatergic transmission? Mol. Neurodegener. 6:55. doi: 10.1186/1750-1326-6-55

Paxinos, G., and Franklin, K. (2012). The Mouse Brain in Stereotaxic Coordinates, 4th Edn. Academic Press, 360.

Rodríguez, J. J., Jones, V. C., Tabuchi, M., Allan, S. M., Knight, E. M., LaFerla, F. M., et al. (2008). Impaired adult neurogenesis in the dentate gyrus of a triple transgenic mouse model of Alzheimer's disease. PLoS ONE 3:e2935 doi: 10.1371/journal.pone.0002935

Rodríguez, J. J., Noristani, H. N., Hilditch, T., Olabarria, M., Yeh, C. Y., Witton, J., et al. (2013). Increased densities of resting and activated microglia in the dentate gyrus follow senile plaque formation in the CA1 subfield of the hippocampus in the triple transgenic model of Alzheimer's disease. Neurosci. Lett. 552, 129-134. doi: 10.1016/j.neulet.2013.06.036

Rodríguez, J. J., Witton, J., Olabarria, M., Noristani, H. N., and Verkhratsky, A. (2010). Increase in the density of resting microglia precedes neuritic plaque formation and microglial activation in a transgenic model of Alzheimer's disease. Cell Death Dis. 1:e1. doi: 10.1038/cddis. 2009.2

Rodríguez, J., Olabarria, M., Rodríguez, J. J., Olabarria, M., Chvatal, A., and Verkhratsky, A. (2009). Astroglia in dementia and Alzheimer's disease. Cell Death Differ. 16, 378-385. doi: 10.1038/cdd.2008.172

Ruat, M., Molliver, M. E., Snowman, A. M., and Snyder, S. H. (1995). Calcium sensing receptor: molecular cloning in rat and localization to nerve terminals. Proc. Natl. Acad. Sci. U.S.A. 92, 3161-3165. doi: 10.1073/pnas.92. 8.3161

Ruat, M., and Traiffort, E. (2013). Roles of the calcium sensing receptor in the central nervous system. Best Pract. Res. Clin. Endocrinol. Metab. 27, 429-442. doi: 10.1016/j.beem.2013.03.001

Small, D. H. (2009). Dysregulation of calcium homeostasis in Alzheimer's disease. Neurochem. Res. 34, 1824-1829. doi: 10.1007/s11064-0099960-5

Vizard, T. N., O'Keeffe, G. W., Gutierrez, H., Kos, C. H., Riccardi, D., and Davies, A. M. (2008). Regulation of axonal and dendritic growth by the extracellular 
calcium-sensing receptor. Nat. Neurosci. 11, 285-291. doi: 10.1038/ nn2044

Vyleta, N. P., and Smith, S. M. (2011). Spontaneous glutamate release is independent of calcium influx and tonically activated by the calciumsensing receptor. J. Neurosci. 31, 4593-4606. doi: 10.1523/JNEUROSCI.6398-1 0.2011

Yano, S., Brown, E. M., and Chattopadhyay, N. (2004). Calcium-sensing receptor in the brain. Cell Calcium 35, 257-264. doi: 10.1016/j.ceca.2003.10.008

Ye, C., Ho-pao, C. L., Kanazirska, M., Quinn, S., Rogers, K., Seidman, C. E., et al. (1997). Amyloid- $\beta$ proteins activate $\mathrm{Ca}^{(2+)} / \gamma(\beta)$-permeable channels through calcium-sensing receptors. J. Neurosci. Res. 47, 547-554. doi: 10.1002/(SICI)1097-4547(19970301)47:5<547::AID-JNR10>3.0.CO;2-V

Ye, C., Kanazirska, M., Quinn, S., Brown, E. M., and Vassilev, P. M. (1996). Modulation by polycationic $\mathrm{Ca}^{2+}$-sensing receptor agonists of nonselective cation channels in rat hippocampal neurons. Biochem. Biophys. Res. Commun. 224, 271-280. doi: 10.1006/bbrc.1996.1019

Conflict of Interest Statement: The authors declare that the research was conducted in the absence of any commercial or financial relationships that could be construed as a potential conflict of interest.

Copyright (C) 2017 Gardenal, Chiarini, Armato, Dal Prà, Verkhratsky and Rodríguez. This is an open-access article distributed under the terms of the Creative Commons Attribution License (CC BY). The use, distribution or reproduction in other forums is permitted, provided the original author(s) or licensor are credited and that the original publication in this journal is cited, in accordance with accepted academic practice. No use, distribution or reproduction is permitted which does not comply with these terms. 